\title{
Development of professional identity and professional socialisation in allied health students: A scoping review
}

\author{
R. Snell ${ }^{1}$, S. Fyfe $e^{1}$, G. Fyfe $e^{1}$, D. Blackwood ${ }^{2}$ \& C. Itsiopoulos ${ }^{3}$
}

\begin{abstract}
Introduction: Reports on the development of professional identity and socialisation in the healthcare professions are mainly from medicine and nursing, although the body of work from other health professions is increasing. This scoping review investigates what is known about the development of professional identity by students from nine allied health professions and what they experience when developing a professional identity.
\end{abstract}

Methods: Reviewers independently searched five databases: CINAHL Plus, Informit, Ovid Medline, Proquest and Scopus, using either terms from text mining six key articles known to the authors or from the keywords: allied health occupation, student, professional identity, professional socialisation, professionalisation and professional role.

Results: Ninety-six articles met inclusion criteria from 3662 records. Over half the articles were published after 2010 and reported studies using qualitative methods with small numbers of participants. Study participants were mainly from the United States of America, the United Kingdom and Australia, and their professions were social work, occupational therapy and physiotherapy. There was no consensus for terminology of professional identity, and related terms were used interchangeably. Theoretical frameworks varied, with situated learning theory and application of standards or frameworks to meet accreditation or professional organisation requirements being most common. Students reported that early introduction to their profession was beneficial to developing a professional identity.

\footnotetext{
Faculty of Health Sciences, Curtin University, Australia

Faculty of Health Sciences \& Vice Chancellery Curtin University, Australia

3 College of Science, Health \& Engineering, La Trobe University, Australia
}

\section{Correspondence}

Robynne Snell

School of Public Health

Faculty of Health Sciences

Curtin University

Kent Street

Bentley, Western Australia 6102

Australia

Tel: +61411136398

Email: robynne.snell@postgrad.curtin.edu.au 
Conclusions: While interest in the development of professional identity has increased, findings indicate that further research, including longitudinal studies, would deepen our understanding of the process of socialisation at different stages and similarities between the professions. This is needed for curriculum development, graduate employability strategies and in order to best prepare students for their future practice.

Keywords: scoping review; professional identity; professional socialisation; professionalisation; allied health occupations; allied health students

\section{Introduction}

The World Health Organisation (WHO) $(1988,2010)$ has long advocated that health professionals need to be competent at working collaboratively in interprofessional teams to improve outcomes for clients. In a Lancet Commission review, Frenk et al. (2010) explain, "Patient management requires coordinated care across time and space, demanding unprecedented teamwork [and] professionals have to integrate the explosive growth of knowledge and technologies while grappling with expanding functions" ( $\mathrm{p}$. 1926). In this increasingly complex workplace, interprofessional teams are promoted to "optimize the skills of their members, share case management and provide better health-services to patients and the community" (WHO, 2010, p. 10). Capability to practice collaboratively is described as "an interprofessional process of communication and decision making that enables the separate and shared knowledge and skills of healthcare providers to synergistically influence patient care provided" (Oandasan \& Reeves, 2005, p. 35). Recognising the interdependence between health and education, reform in professional education is recommended to produce graduates who are able to efficiently deliver healthcare as members of teams (Frenk et al., 2010).

Each profession has its own professional identity (PI) and culture, with values, beliefs, patterns of behaviour and attitudes being reinforced during education (Hall, 2005). The strength of PI is important, as it relates to the ability to interact in collaborative practice and the degree of participation in the team (Adams et al., 2006; Hean \& Dickenson, 2005). Adams and colleagues (2006), surveying a sample of 1254 firstyear students from 10 health and social care professions, found students entered their course with an existing PI, and this was stronger for some professions than others. They identified predictors for the strength of a student's PI, with the highest being for physiotherapy students with previous experience in health and social care settings and more understanding of teamwork, knowledge of their profession and cognitive flexibility (Adams et al., 2006).

During formation of PI, the individual's own culture merges with the culture of the profession (Ajjawi \& Higgs, 2008), and roles, values and attitudes of the profession are internalised (Bartlett et al., 2009) in a process called professional socialisation (PS). Learning to become a professional requires more than just learning skills and behaviours; it is both a cognitive and cultural activity (Dahlgren et al., 2004; du Toit, 1995; Howkins \& Ewens, 1999). 
For new graduates, early years in the workforce are exciting, rewarding and challenging, and also a significant time for PI development (Ajjawi \& Higgs, 2008; Black et al., 2010). In a small study of graduate allied health professionals transitioning from classroom to practice, the first year was characterised by constant stress, affecting aspects of personal and professional life, continuous professional development and, finally, adaptation (Tryssenaar \& Perkins, 2001). Preparing graduates for the workforce who are able to meet employer demands for practitioners and who are work-ready with technical knowledge, professional competencies and other work related skills is a concern for universities (M. Clarke, 2017; Smith \& Pilling, 2007). Graduate employability is multifactorial and ideally brings together governments, employer groups and industry to identify critical issues and initiate strategies to enhance employment prospects and support graduates transitioning into the workforce (Bennett et al., 2016; M. Clarke, 2017; Daniels \& Brooker, 2014).

Reports on the development of PI and PS in healthcare professions are mainly from medicine and nursing, with relatively newer work from physiotherapy, occupational therapy, psychology and dietetics (Bartlett et al., 2009; Cruess et al., 2014; MacLellan et al., 2011). Although referring to the development of professional identity in dietetics, MacLellan and colleagues (2011) conclude, "The wealth of material from nursing indicates dietetics has much to explore" (p. 41). They observe that whilst the process may potentially be similar between dietetics and nursing, the focus of the professions is different, and therefore, professionalisation is likely to be qualitatively different. It seems reasonable to assume this rationale could also apply to other allied health professions.

A greater understanding of how allied health students develop their PI would facilitate better preparation of students for entry to the workforce and support them through the challenging early years of practice. It would also promote curriculum development and professional development of educators and practitioners. This scoping review set out to establish what is known about the development of professional identity of allied health students and their experience as they develop their professional identity. Consistent with the purpose of undertaking a scoping review, the secondary aim is to identify gaps in the literature on formation of PI by allied heath students and provide directions for further research.

\section{Method}

The framework approach for conducting scoping reviews as outlined by Arksey and O'Malley (2005), with supporting commentaries by Daudt and colleagues (2013) and Levac and colleagues (2010), was used to guide this scoping review, which followed the sequence: identifying the research questions; identifying relevant studies; study selection charting or extracting the data; and collating, summarising and reporting the results. The optional stages of critical appraisal or quality assessment of studies and expert consultation were omitted (O'Brien et al., 2016). Ethical approval was not required. 


\section{Scoping study protocol}

A protocol was developed prior to conducting the review although not registered.

\section{Inclusion criteria}

The term "allied health" represents a collective of health disciplines, exclusive of doctors and nurses and tends to be used at "service delivery and policy levels" (Mason, 2013, p. 300). However, there is wide variation and no agreement on which professions are considered to be allied health (Demo et al., 2015; Grimmer et al., 2014; Turnbull et al., 2009). For this scoping review, Allied Health Professions Australia's (2017) definition that allied health professions have "clearly articulated national entry level competency standards and assessment procedures, a defined core scope of practice, a direct patient care role and may have application to broader public health outcomes" will be used (para. 4). According to Australian Allied Health Leadership Forum (2018), "allied health professionals are qualified to apply their skills to retain, restore or gain optimal physical, sensory, psychological, cognitive, social and cultural function of clients, groups and populations" (para. 1). It is well accepted that medical, nursing or dental professionals are not included as allied health professionals, and this position is consistent internationally (The Association of Schools of Allied Health Professions, 2015; National Library of Medicine, 2018).

In this paper, "student" means a person enrolled in a formal undergraduate or postgraduate program at college or university that leads to a qualification in allied health and must be completed prior to registration or the equivalent licensing with relevant accrediting body (National Library of Medicine, 2018). A clinical training program or professional placement is a requirement of the course or program, with setting and duration varying according to the profession (Mason, 2013; McAllister \& Nagarajan, 2015).

Participants were to be students from one or more of the following allied health professions: audiology, human nutrition and dietetics, occupational therapy, physiotherapy, podiatry, pharmacy, psychology, social work or speech pathology.

These were selected because their roles are similar in the practice setting (Grimmer et al., 2014). Studies with students from unspecified allied health professions and other allied health professions were eligible. Studies with students from medicine, dentistry and nursing were considered only if they included students from one of the included allied health professions.

Studies needed to both:

- address the development of professional identity (PI) or development of a professional self or professional socialisation (PS) as the intervention or phenomena of interest

- be undertaken in a health education setting, such as a university classroom or professional practice placement. 
Primary or original research could have outcomes such as: student reports of acquisition or changes in knowledge, skills, attitudes, feelings or behaviours related to PI, professional role or professional practice; education activities with learning outcomes related to PI; development of tools and reports on measures of students' PI; or discussion of attributes or qualities or other characteristics in PI development. Quantitative studies, studies reporting qualitative data, studies with mixed method data as well as expert opinion and discussion papers published in peer-reviewed journals were suitable. Grey literature, such as conference proceedings, government and other non-commercial reports, were not included in the search. The search was extended back to 1960 for articles published in English.

\section{Identifying relevant studies}

To avoid duplicating work by other researchers (Tricco et al., 2016), repositories of registered protocols (Campbell Collaboration Library, Joanna Briggs Institute Library and Prospero Library) were searched, however we were unable to retrieve any similar work.

Five databases, CINAHL Plus, Informit, Ovid Medline, Proquest and Scopus, were searched in a three-step strategy. Text-mining was undertaken by one author (DB, Faculty of Health Science librarian) on six key articles already known to the authors (Adams et al., 2006; Ajjawi \& Higgs, 2008; Bartlett et al., 2009; Clouder, 2003; MacLellan et al., 2011; Trede et al., 2012). This process identified relevant keywords and subject headings, which were then searched in Medline and CINAHL in the title and abstract fields. Simultaneously, another reviewer (RS) independently searched the same databases using authors' keywords from the same articles. These were: allied health occupation, student, professional identity, professional socialisation, professionalisation and professional role. A final search using keywords was adapted for the remaining databases (Informit, Proquest and Scopus) and was conducted independently by two reviewers (RS and SF).The search string was: (allied health occupation* OR allied health profession OR allied health personnel OR audiolog* OR physiotherap* OR physical therap* OR occupational therap* OR speech therap* OR speech patholog* OR diet* OR nutrit* OR social work* OR psycholog* OR podiatr* OR pharmac*) AND (student* OR pre-licens* OR prelicens* OR pre-registration OR preregistration) AND (professional identity OR professional sociali\$ation OR professional role OR professionali\$ation OR sociali\$ation). The search strategy for Ovid Medline is shown in the appendix.

\section{Study selection}

An article was included if it was considered eligible by the two reviewers. Articles accepted by only one reviewer went to the third reviewer (GF) for a decision. Inclusion and exclusion criteria are shown in Table 1. 


\section{Table 1}

Inclusion and Exclusion Criteria

\begin{tabular}{|c|c|c|}
\hline Criterion & Inclusion & Exclusion \\
\hline Time period & 1960 onwards & Nil \\
\hline Language & Published in English & Article not available in English \\
\hline Type of article & $\begin{array}{l}\text { Original research article published in peer- } \\
\text { reviewed journal }\end{array}$ & $\begin{array}{l}\text { Articles not reporting original research, such as } \\
\text { book chapters, newspaper articles } \\
\text { Other types of publication, such as conference } \\
\text { proceedings, PhD theses, government reports }\end{array}$ \\
\hline Study focus & $\begin{array}{l}\text { Development of professional identity; } \\
\text { or development of professional self; or } \\
\text { professional socialisation }\end{array}$ & $\begin{array}{l}\text { Interprofessional education, such as studies } \\
\text { that reported on interprofessional education } \\
\text { activities (IPE) or collaborative practice activities } \\
\text { that engaged students from two or more } \\
\text { professions } \\
\text { Articles reporting on conceptual aspects of IPE }\end{array}$ \\
\hline Setting & $\begin{array}{l}\text { Health education such as university classroom } \\
\text { Healthcare such as professional practice } \\
\text { placements }\end{array}$ & Setting not specified \\
\hline $\begin{array}{l}\text { Geographical } \\
\text { place of study }\end{array}$ & International & Nil \\
\hline $\begin{array}{l}\text { Population } \\
\text { and sample }\end{array}$ & $\begin{array}{l}\text { Students from: } \\
\text { Audiology, human nutrition and dietetics, } \\
\text { occupational therapy, physiotherapy, podiatry, } \\
\text { pharmacy, psychology, social work or speech } \\
\text { pathology } \\
\text { Allied health students, profession may or may } \\
\text { not be specified }\end{array}$ & $\begin{array}{l}\text { Studies that reported on students from medicine, } \\
\text { dentistry and nursing as a single discipline } \\
\text { Studies reporting on practitioners' or lecturers' } \\
\text { own experience of professional identity }\end{array}$ \\
\hline
\end{tabular}

\section{Data charting}

A charting table or data extraction form to record key information was included in the protocol, trialled by the three reviewers and refined as the review progressed. One reviewer (RS) charted the data, which was verified with another reviewer (SF) after charting from $10 \%$ of articles was completed to ensure accuracy and completeness. The first reviewer completed charting from the remaining articles.

\section{Data management}

The searches were performed directly in each of the databases and citations exported to reference management software Endnote (Version 7.8). The review used Rayyan (Version 1), a cloud-based application developed to expedite screening and file sharing for systematic reviews (Ouzzani et al., 2016). The titles and abstracts of references were imported into Rayyan from Endnote, in RIS format, and a PDF of full text articles uploaded to facilitate blind review at each stage, with results exported from Rayyan as a CSV file. An Excel for Mac spreadsheet (Version 14.7) was also used to record reviewer decisions. 


\section{Data analyses and synthesis}

Data for descriptive analysis were entered into Excel using the charting table. Qualitative analysis was conducted in NVivo for Mac (Version 11.4). Included articles were imported in PDF format, reviewed and coded for themes. Auto coding was applied for the keywords and then themes and subthemes identified in an iterative process, using the constant comparative method (Liamputtong, 2013). The final stage involved synthesis of themes into a research question focused, integrated summary.

\section{Results}

Database searches were conducted in May 2016 and updated in April 2017. Three thousand six hundred and sixty-two records were retrieved, and 96 articles met inclusion criteria and were retained. Shown in Figure 1 is a PRISMA flow chart describing the study selection (Liberati et al., 2009). Studies were excluded if the study focus was not relevant, the article was unavailable in electronic format or study participants were not suitable. Following discussion between reviewers, studies on interprofessional education (IPE), including clinical education activities, were excluded, as emerging literature on dual professional identities indicated that IPE articles would not address the review questions and may confound the understanding of professional identities (Joynes, 2018; Khalili et al., 2013).

\section{Description of retrieved articles}

More than half of the included articles were published after 2010 (54,56.3\%), used qualitative research methods $(51,53.1 \%)$ and had less than 50 participants $(53,55.2 \%)$, and included PI $(37,38.5 \%)$ or PS $(18,18.8 \%)$ in the objectives, shown in Tables 2-8.

Few studies $(21,21.9 \%)$ used a quantitative research design, and missing information such as study design or sample size was recorded as "not known". In particular, some authors only stated whether the study was quantitative or qualitative and the method of data collection (Bartlett et al., 2009; Bonsaksen et al., 2013; Brown et al., 2001; Collins et al., 2011; Furze et al., 2011; Hantman \& Ben-Oz, 2014; Johnson \& Chauvin, 2016; Noble, Coombes, Nissen et al., 2015; Noble, O'Brien et al., 2014; Roche \& Coote, 2008; Santasier \& Plack, 2007; Taylor \& Harding, 2007; Turpin et al., 2013; Whitcombe, 2013). The most frequent student professions were social work (26, $27.0 \%)$, occupational therapy $(23,23.9 \%)$ and physiotherapy $(19,19.8 \%)$. A small number of studies were multi-professional $(6,6.3 \%)$, reporting students from two or more professions working separately, and some studies $(13,13.5 \%)$ included other participants, such as graduates, clinicians and practitioners, and clinical and faculty educators. Less than $10 \%$ of articles were published in an allied health journal, with the trend towards discipline-specific education and professional practice journals (see Table 9: Name of Journal and Frequency of Articles Included in the Review). Full descriptive table format of the results is available from the authors on request. 
SCOPING REVIEW: DEVELOPING PROFESSIONAL IDENTITY AND PROFESSIONAL SOCIALISATION

\section{Figure 1}

\section{PRISMA Flow Chart Describing the Study Selection}

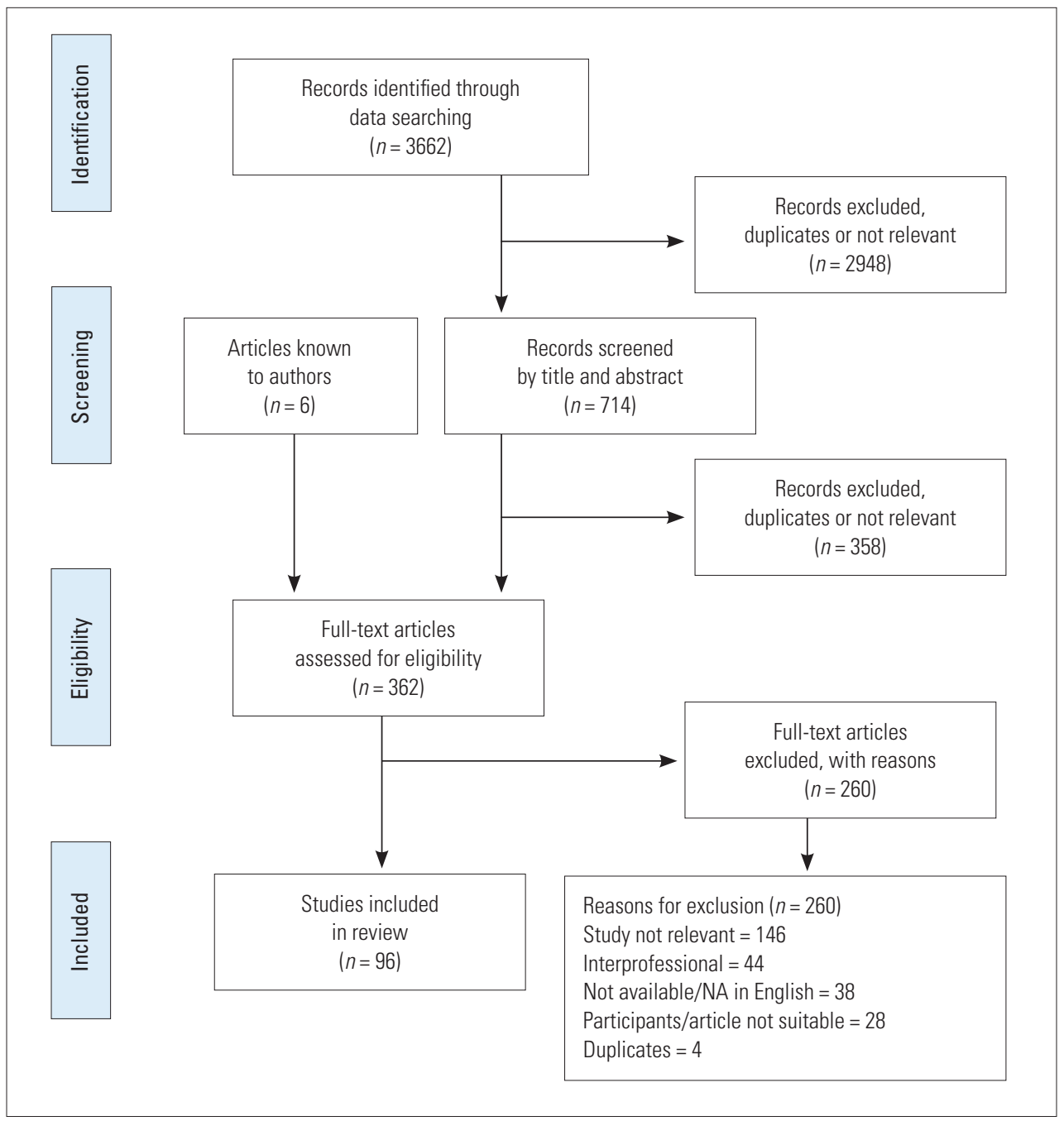

Adapted from: Liberati et al. (2009) The PRISMA statement for reporting systematic reviews and meta-analyses of studies that evaluate healthcare interventions: Explanation and elaboration. Annals of Internal Medicine, 51(4), W65-W94. doi:10.7326/0003-4819-151-4-200908180- 
SCOPING REVIEW: DEVELOPING PROFESSIONAL IDENTITY AND PROFESSIONAL SOCIALISATION

\section{Table 2}

Year of Publication: Summary of Retrieved Articles $(n=96)$.

\begin{tabular}{c|c}
\hline No. & Year range \\
\hline 54 & $2011-2017$ \\
34 & $2001-2010$ \\
8 & $1971-2000$ \\
\hline
\end{tabular}

\section{Table 3}

Research Design: Summary of Retrieved Articles $(n=96)$.

\begin{tabular}{c|l}
\hline No. & Methodology \\
\hline 51 & Qualitative \\
\hline 14 & Phenomenology \\
12 & Not known \\
4 & Interpretative \\
4 & Case study \\
3 & Content analysis \\
8 & Ethnography (2), Grounded theory (2), Multi case study (2), \\
& Narrative (2) \\
6 & Consensual qualitative research (1), Delphi technique (1), Discourse (1), \\
\hline 21 & Exploratory (1), Framework analysis (1), Template analysis (1) \\
\hline 8 & Ouantitative \\
\hline 7 & Correlational \\
4 & Cuasi-experimental \\
2 & Cohort (1), Cross section (1), Experimental (1), Exploratory (1) \\
\hline 12 & Mot known \\
\hline 12 & Othed methods \\
\hline 9 & Literature review \\
2 & Opinion \\
\hline 1 & Time geographic \\
\hline
\end{tabular}

\section{Table 4}

Sample Size: Summary of Retrieved Articles $(n=96)$.

\begin{tabular}{c|l}
\hline No. & Number of participants \\
\hline 53 & $<50$ \\
13 & $50-99$ \\
9 & $100-299$ \\
9 & $\geq 300$ \\
11 & Not relevant \\
1 & Not known \\
\hline
\end{tabular}


SCOPING REVIEW: DEVELOPING PROFESSIONAL IDENTITY AND PROFESSIONAL SOCIALISATION

\section{Table 5}

Country of Participants: Summary of Retrieved Articles $(n=96)$.

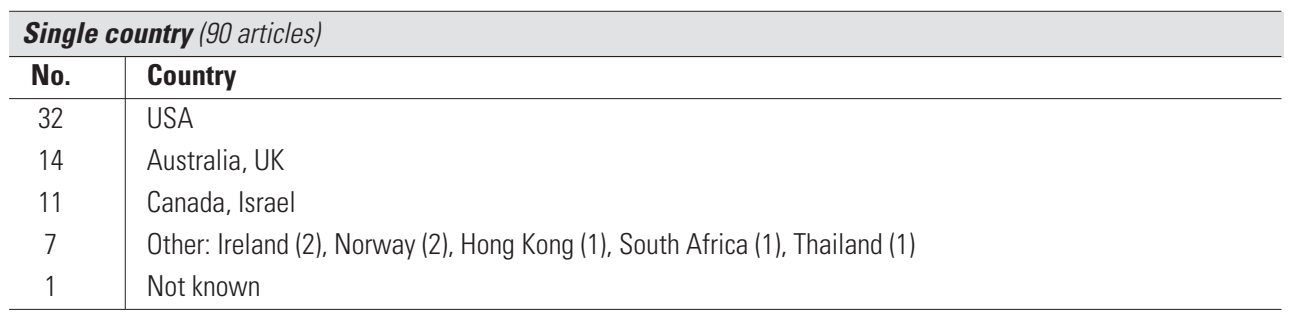

\begin{tabular}{c|l}
\hline \multicolumn{2}{l}{ Multi country* (6 articles) } \\
\hline No. & Country \\
\hline 1 & 5 countries: Australia, Canada, Ireland, UK and USA \\
1 & 3 countries: Norway, Denmark and Sweden \\
4 & 2 countries: UK and Sweden (2), UK and Australia (1), USA and Scotland (1) \\
\hline
\end{tabular}

* Students from two or more countries working separately

\section{Table 6}

Profession of Participants: Summary of Retrieved Articles ( $n=96)$.

\begin{tabular}{l|l}
\hline \multicolumn{2}{l}{ Single profession (90 articles) } \\
\hline No. & Profession \\
\hline 26 & Social work \\
23 & Occupational therapy \\
19 & Physiotherapy \\
13 & Pharmacy \\
7 & Dietetics \\
1 & Psychology \\
1 & Not relevant \\
\hline
\end{tabular}

\begin{tabular}{c|l}
\hline \multicolumn{2}{l}{ Multi profession* (6 articles) } \\
\hline No. & No. of professions \\
\hline 2 & 4 professions: medicine, nursing, dental and pharmacy \\
13 & professions: occupational therapy, podiatry and paramedic \\
32 & professions: occupational therapy and physiotherapy (2), occupational therapy and dietetics (1) \\
\hline
\end{tabular}

* Students from two or more professions working separately 
SCOPING REVIEW: DEVELOPING PROFESSIONAL IDENTITY AND PROFESSIONAL SOCIALISATION

\section{Table 7}

Type of Student Experience (74 articles).

\begin{tabular}{l|l}
\hline No. & Student experience \\
\hline 36 & Whole of course or program \\
\hline 28 & Component of the course or program: \\
& Non-traditional placements (10) \\
& Clinical experience (8) \\
& Service learning (5) \\
& Module (4) \\
& Community of practice (1) \\
\hline 10 & Student views: perception (8), expectation (1), motivation \& values (1) \\
\hline
\end{tabular}

\section{Table 8}

Focus of the Study: Summary of Retrieved Articles $(n=96)$.

\begin{tabular}{c|l}
\hline No. & Focus \\
\hline 96 & Objectives \\
\hline 37 & Professional identity (27), Identity (10) \\
18 & Professional socialisation (17), Socialisation (1) \\
7 & Professionalism (7) \\
5 & Professional values (5) \\
5 & Professional behaviour/s (4), Professional behaviours and values (1) \\
18 & Other: Placement design (6), Confidence/professional (2), Reflection (2), Role model/s (2), Community of \\
& practice (1), Personal growth (1), Student readiness (1) \\
\hline 6 & Other: Not related to research questions (6) \\
\hline 75 & Title or keywords \\
\hline 27 & Professional identity (22), Identity (4), Personal and professional identities (1) \\
24 & Professional socialisation (16), Socialisation (4), Professionalisation (3), Formal socialisation (1) \\
8 & Professionalism (8) \\
3 & Professional behaviour/s (3) \\
7 & Other: Role model/s (2), Personal growth (1), Professional confidence (1), Professional development (1), \\
2 & Professional formation (1), Student readiness (1) \\
& Other: difficult to separate: Confidence and professional identity (1), Identity and professional socialisation \\
4 & (1) \\
\hline 21 & Other: not related to research questions (4) \\
\hline 7 & Abstract only \\
7 & Professional identity (6), Identity (1) \\
3 & Professional socialisation (4), Formal socialisation (1), Professionalisation (1), Socialisation (1) \\
1 & Other: Professional development (2), Professional growth (1) \\
\hline
\end{tabular}


SCOPING REVIEW: DEVELOPING PROFESSIONAL IDENTITY AND PROFESSIONAL SOCIALISATION

\section{Table 9}

Name of Journal and Frequency of Articles Included in the Review $(n=96)$.

\begin{tabular}{|c|c|}
\hline No. & Name of Journal \\
\hline 9 & Social Work Education \\
\hline 8 & Journal of Physical Therapy Education \\
\hline 6 & American Journal of Pharmaceutical Education, British Journal of Occupational Therapy \\
\hline 5 & Canadian Journal of Dietetic Practice and Research \\
\hline 4 & Australian Occupational Therapy Journal, Journal of Social Work Education \\
\hline 3 & Journal of Allied Health, Journal of Teaching in Social Work \\
\hline 2 & $\begin{array}{l}\text { Clinical Supervisor, International Journal of Pharmacy Practice, Medical Education, Medical Teacher, } \\
\text { Nutrition and Dietetics, Occupational Therapy International, Pharmacy Practice, Physiotherapy Theory and } \\
\text { Practice, Studies in Higher Education }\end{array}$ \\
\hline 1 & $\begin{array}{l}\text { Advances in Health Science Education, Canadian Journal of Occupational Therapy, Counselling Psychology } \\
\text { Quarterly, Currents in Pharmacy Teaching and Learning, Focus on Health Professional Education: A Multi- } \\
\text { Disciplinary Journal, International Social Work, Health and Social Care in the Community, Internet Journal } \\
\text { of Allied Health Sciences and Practice, Journal of Education for Social Work, Journal of Health and Social } \\
\text { Behavior, Journal of Human Behaviour in the Environment, Journal of Medical Education, Journal of } \\
\text { Occupational Science, Journal of Pharmacy Teaching, Journal of Practice Teaching and Learning, Journal } \\
\text { of Social Service Research, Journal of Social Work, Learning in Health and Social Care, Occupational } \\
\text { Therapy Journal of Research, Pharmacy Education, Physical Therapy, Physiotherapy Canada, Physiotherapy } \\
\text { Research International, Scandinavian Journal of Occupational Therapy, Social Science \& Medicine, Medical } \\
\text { Psychology and Medical Sociology, South African Journal of Occupational Therapy, Symbolic Interaction, } \\
\text { The Journal of Mental Health Training Education and Practice, Work. }\end{array}$ \\
\hline
\end{tabular}

\section{Findings from the retrieved articles}

The terms professional identity, professional socialisation, professionalisation and professionalism, professional behaviour and even professional role are interrelated concepts. Sometimes the terms were used interchangeably or assumed an understanding, and of the 96 articles in this review, less than two thirds (61, 63.5\%) either defined or described the terms used.

Only 24 articles (25\%) defined or described PI, and despite the lack of consistency, values, attitudes and beliefs were core aspects of the definitions and descriptions. Ten articles (Ashby et al., 2016; Binyamin, 2017; Boehm et al., 2015; C. Clarke et al., 2014; Lahav et al., 2017; Levy et al., 2014; Mylrea et al., 2015; Noble, O’Brien et al., 2014; Scholar et al., 2014; Shlomo et al., 2012) cited the definition of PI proposed by Adams et al. (2006), that it is the "attitudes, values, knowledge, beliefs and skills that are shared with others within a professional group and relates to the professional role being undertaken by the individual" (p. 56). This can be summarised as "the sense of being a professional" (Paterson et al., 2002, p. 6). Student views of PI differed, with interpretations being "in relation to desired traits" or "a process in which each individual comes to have a sense of themselves" (Wiles, 2013, p. 854). More authors $(27,28.1 \%)$ defined or described PS, or the process of developing PI, rather than the concept of development (for example, Loseke \& Cahill, 1986; MacLellan et al., 2011; O'Loughlin et al., 2005). Although similar and linked, professional socialisation is different to development of professional identity (Noble, Coombes, Shaw et al., 2014) 
and described as "the process by which people selectively acquire the values and attitudes, the interests, skills and knowledge-in short, the culture-current in groups of which they are, or seek to become, a member" (Merton et al., 1957, p. 283, as cited in Clouder, 2003 , p. 213). Other authors $(10,10.4 \%)$ defined professionalism and professional behaviour (for example, Lerkiatbundit, 2006; Robinson et al., 2012; Santasier \& Plack, 2007). Professionalism is "specific knowledge, attitudes, and values—all manifested by professional behaviours" (Robinson et al., 2012, p. 276) while professional behaviours are "complex and evolving" (Grace $\&$ Trede, 2013, p. 793), defined as "behaving in a manner to potentially achieve optimal outcomes in professional tasks and interactions" (Jee et al., 2017, p. 976).

These findings on the concepts surrounding PI are similar to Trede and colleagues (2012), who observed the term "professional" applied to a "variety of different contexts" (p. 374) rather than a definition. Noble, O’Brien and colleagues (2014) also found no agreed PI definition except that it is "seen as the result of the interaction between self and context" (p. 377).

Less than two thirds of articles $(59,61.5 \%)$ addressed any theoretical framework, with some authors providing a framework and no overview of their terms, and vice versa. The theoretical framework most frequently referred to was "situated learning in a community of practice" developed by Lave and Wenger, where "professional identities are understood to be constructed through an evolutionary and iterative process, resulting in an individual developing a sense of a professional self" (as cited in Noble, O'Brien et al., 2014, p. 377). This was applied in 17 articles (17.8\%) (Binyamin, 2017; Boehm et al., 2015; Bonsaksen et al., 2013; Clouder, 2003; Davis, 2006; Hayward \& Li, 2014; Jee et al., 2017; Lindquist et al., 2006a, 2006b; Mylrea et al., 2015; Noble, Coombes, Nissen et al., 2015; Noble, Coombes, Shaw et al., 2014; Noble, O'Brien et al., 2014; Osteen, 2011; Skøien et al., 2009; Trede et al., 2012; Wiles, 2013), with "community of practice" being raised in the discussion or findings by many others. The framework can be summarised as "participation in social relationships and peripheral activities in the community of practice, in which novices become acquainted with the tasks, vocabulary and the organizing principles of the community" (Binyamin, 2017, p. 4).

The second most prominent framework was the application of guidelines by a professional organisation, often attributable to regulation and accreditation requirements, in 16 articles (16.7\%) (Anderson \& Irwin, 2013; Ashby et al., 2016; Crandell et al., 2013; Grace \& Trede, 2013; Hayward \& Li, 2014; Knightbridge, 2014; Lindsey, 2005; Miller, 2010, 2013; Mylrea et al., 2015; Osteen, 2011; Rutter \& Duncan, 2010; Scholar et al., 2014; Turpin et al., 2012; Wiles, 2013; Wise \& Yuen, 2013), from the professions of social work (6), pharmacy (4), physiotherapy (4) and occupational therapy (2).

Student experiences were addressed in 74 studies (77.0\%), although of these, only $30(40.5 \%)$ related to PI. A range of student experiences was reported, most often concerning the whole course or program $(36,48.6 \%)$ or a component $(28,37.8 \%)$ and less frequently $(10,13.5 \%)$ about student perceptions and values, shown in Table 2. Commitment by students to engage in their own learning was determined to be essential 
in PI development (Trede et al., 2012), with reflection (Bartlett et al., 2009; Greenfield et al., 2015), self-authorship (Johnson \& Chauvin, 2016) and agency (Clouder, 2003) potentially beneficial strategies. Professional self-confidence affected students' clinical decision making, development of competency and professional identity, and improved with experience (Greenfield et al., 2015; Holland et al., 2012; Swanepoel et al., 2016; Tryssenaar \& Perkins, 2001). Students acknowledged ownership of their role in development of PI (Davis, 2006), in contrast with several authors who considered that lecturers and clinical educators should lead the process and give support to the student (Paterson et al., 2002; Taylor \& Harding, 2007).

Eight articles (8.3\%) aimed to influence PI development via the curriculum (Ashby et al., 2016; Canavan, 2009; Hayward \& Li, 2014; Johnson \& Chauvin, 2016; Noble, Coombes, Nissen et al., 2015; Noble, Coombes, Shaw et al., 2014; Noble, O’Brien et al., 2014; Taylor \& Harding, 2007) or curriculum review (Boehm et al., 2015; Ikiugu \& Rosso, 2003). Miller (2013) identified elements of an implicit and explicit curriculum, linking it to PS that occurs at the "essential intersection of classroom and field" (p. 383). Students considered practice education the most significant course factor to influence PI development and felt conflicted when there were discrepancies or dissonance between the course and what occurred in practice (Ashby et al., 2016; Davis, 2006). Ashby et al. (2016) investigated students from five countries, finding professional education, PS and curriculum had the greatest influence on PI formation. Responsibility to lay foundations for PI development throughout the curriculum is firmly placed with educators by many authors (Bartlett et al., 2009; Paterson et al., 2002; Richardson et al., 2002; Trede et al., 2012; Tsoumas \& Pelletier, 2007). Knowing about the profession is a predictor for PI strength (Adams et al., 2006), however this was a gap in students' knowledge shown across pharmacy (Taylor \& Harding, 2007), occupational therapy (Turpin et al., 2012), social work (Canavan, 2009) and dietetics (MacLellan et al., 2011). Preparing students for the realities of practice was examined by 10 authors (10.4\%) (Bartlett et al., 2009; Canavan, 2009; Davis, 2008; MacLellan et al., 2011; Noble, Coombes, Nissen et al., 2015; Noble, Coombes, Shaw et al., 2014; Noble, O’Brien et al., 2014; Shuval \& Adler, 1979; Swanepoel et al., 2016; Tryssenaar \& Perkins, 2001), with authentic real world experiences being significant for formation of PI (Ashby et al., 2016; Gazzola et al., 2011; Mylrea et al., 2015; Trede et al., 2012).

According to situated learning theory, student learning takes place and social identities are developed by participating in a community of practice (Osteen, 2011; Skøien et al., 2009). In a community of practice "mutual engagement, joint enterprise and shared repertoire" are necessary to sustain the community (Davis, 2006, p. 3), with each dimension contributing to student learning. Students perceived interactions in the professional community of practice vital to their learning (Davis, 2006), consistent with other researchers' findings that student learning in the practice setting is shaped by the quality of experiences (Holland et al., 2012; Skøien et al., 2009), especially the relationship with supervisors (Levy et al., 2014) and general inclusiveness (Davis, 2006). The community of practice played a fundamental role in reinforcing professional values and PI development for students on fieldwork (Davis, 2006; Paterson et al., 2002), and 
resonance between their personal and professional values was important to students (Burford et al., 2014; Gazzola et al., 2011; Osteen, 2011; Paterson et al., 2002) and the profession (Barretti, 2007). A key finding was that PI development is delayed if introduction to the practice setting doesn't occur until late into the course (MacLellan et al., 2011; Taylor \& Harding, 2007), with practice education bridging "theory-based learning at university and practice settings" (Ashby et al., 2016, p. 234).

\section{Discussion}

The aim of this scoping review was to establish what is known about development of PI by allied health students, and their experience of PS, in order to identify gaps in the literature. Although terms used by authors were varied, the focus of formation of PI and PS, referring to the process of development of PI, was frequently investigated from an academic or discipline perspective rather than the students' experience. Other authors evaluated professionalism and professional behaviours as indirect measures of PI and PS. Trede et al. (2012) offered a possible explanation for the variation in understanding of identity - it is quite simply "difficult to define" (p. 380), suggesting this is the reason many articles lack depth when discussing PI. Without a consistent interpretation of PI as the basis, theoretical frameworks and other ensuing arguments inevitably take a varied stance, as demonstrated in the range of focus for articles retrieved for this review.

The framework most commonly adopted by authors was the "community of practice" by Lave and Wenger, who proposed learning takes place in social relationships through informal sharing of information, not just acquisition of knowledge (as cited in Li et al., 2009). Also known as "situated learning theory", this work advises that learning should take place in a setting the same as where the knowledge will be used (Li et al., 2009). Work by Ranmuthugala and colleagues (2011) investigated communities of practice in the healthcare sector, but they explored allied health student experiences across several settings, not just healthcare. Participants in the community of practice are considered "stakeholders", and allied health students will engage in various ways and depth with multiple stakeholders in the "landscape of practice" (Jackson, 2017, p. 925), including professional organisations, academic staff and curricula, community groups, student societies, employers and university student support and careers services. A small number of studies retrieved in this review $(13,13.5 \%)$ involved non-student participants - graduates, clinical and education supervisors, other faculty and university staff and, much less commonly, service users or clients. However, there is a gap in the literature that integrates these stakeholders with allied health students, professional organisations and student and career services (Jackson, 2017). Understanding the role and contribution in the development of PI in a broader range of settings and with more diverse stakeholders would support strategies to enhance student engagement and work-readiness (Daniels \& Brooker, 2014; Jollands et al., 2015).

Cruess and colleagues (2014) challenge the traditional notion that the aim of teaching professionalism is to ensure acquisition of professional behaviour, considering the implicit purpose has always been to help students develop their professional identities. With curricula in mind, Trede and colleagues (2012) asked universities to "prepare 
graduates for the world of work" (p. 379) and cites Clouder (2005) who urged academics to consider what is taught and assessed when preparing students for the realities of practice.

Graduate employability is important to universities, and preparing graduates for the workforce was explored by Jackson (2017), who proposed the contemporary version of employability and work-readiness is construction of a professional identity, with students' maturation starting at "pre-professional identity" (p. 926). Bennett et al. (2016) and Jollands et al. (2015) in separate reports on graduate employability, acknowledge the complexity of the issues and suggest many graduates are not as prepared for the workforce as employers require. With these reports in mind, further research on the strength of professional identity of allied health students and how that relates to graduate employability is warranted.

The protective effect of a strong PI was thought to equip students for future practice in complex health settings (Lindquist et al., 2006b; Mylrea et al., 2015), and concerns about a weak PI were discussed by many (Boehm et al., 2015; Canavan, 2009; Davis, 2006; Ikiugu \& Rosso, 2003; Lindquist et al., 2006b; Loseke \& Cahill, 1986; Miller, 2010; Noble, O’Brien et al., 2014). Trede (2012) argues, "Universities need to claim their role in PI development" (p. 379), while Adams, taking this further, is interested in student progression through a course and into careers, and questions how PI might "impact on practice and, ultimately, on patient care" (Adams et al., 2006, p. 65). We found few articles capable of addressing this—one study using purposive sampling included alumni (Miller, 2013) as participants, and seven studies with undergraduate enrolments were longitudinal (Clouder, 2003; Gould, 1993; Jee et al., 2017; Lahav et al., 2017; Lindquist et al., 2006a; Pullen Sansfaçon \& Crête, 2016; Tryssenaar \& Perkins, 2001), with two of these following graduates into the workforce (Lindquist et al., 2006a; Tryssenaar \& Perkins, 2001).

Frenk and colleagues (2010) consider redesigning health education to meet 21 st century healthcare needs would incorporate a "new professionalism" and "promote quality, embrace teamwork, uphold a strong service ethic, and be centred around the interests of patients and populations" (p. 1946). Accreditation frameworks and regulating curriculum are seen as the means to bring about reform and reshape the healthcare workforce (Holmboe \& Batalden, 2015; Wilkes et al., 2018) and were represented in a proportion of the retrieved articles. The extent or rate of reform occurring in allied health education through this mechanism was not clear, and McAllister and Nagarajan (2015) alluded that universities may be being constrained by outdated allied health accreditation requirements. More specifically, further research clarifying the dynamic relationship between accreditation requirements, the influence of curriculum reforms and formation of students' professional identity would inform universities and enhance readiness of graduates for practice in the health workforce.

Paucity of information was universally expressed as the reason for conducting the research by authors, along with calls to resolve terminology and further research to conceptualise professional identity, the processes and pedagogy. In part, this is due to the studies themselves - many conducted over a short period of time with a small 
number of participants. Reliance on convenience samples with volunteers, employing a qualitative research design and not being able to generalise findings to other settings or professions were also common. Our findings indicate that while interest has increased, the area lacks longitudinal research on the experience of students prior to and after graduation to enable a better understanding of development at different stages and large-scale studies to identify variation between professions and settings. Greater participation and integration of findings from other stakeholders in the community of practice, such as student career services, allied health professional organisations and employers would support better preparation of graduates for the workforce.

\section{Limitations}

The purpose and focus of this review is the development of professional identity by allied health students, with studies excluded if students were from nursing, medicine or dentistry as a single profession. While the body of work from these professions and lessons for allied health are acknowledged, we believe there is sufficient difference in professional roles to warrant specific attention on students enrolled in programs for allied health professions. The specified allied health professions were limited to nine and the number of databases to five. Researchers from other allied health professions may be publishing research in this area using different keywords or publishing in journals not in the selected databases. Similarly, only peer-reviewed articles were included, and conference proceedings, government reports and other non-commercial grey literature may have provided further articles for consideration. Research on interprofessional education was excluded from this review to maintain emphasis on individual professional identity development and to minimise the influence of dual or multiple identities, and this may have excluded some potentially relevant articles. The reviewers only screened articles in English that were available electronically, but it is thought the final number reviewed (96) was sufficient to address the research questions. Some professions were underrepresented, which seems most likely to be due to scarcity of research rather than issues identifying published articles.

\section{Conclusions}

This scoping review found terminology around professional identity without a consistent definition and the interchangeable use of interrelated terms. Theoretical frameworks used to explore PI varied, however those most commonly adopted were situated learning theory and standards or frameworks to meet requirements of accreditation or allied health professional organisations, with education reforms beginning to emerge through this mechanism. Findings of the review showed early introduction of students to the profession and communities of practice are beneficial to PI formation, and this is enhanced when students are given opportunities throughout the curriculum to reflect and articulate their experiences. Consolidating terminology and further research using longitudinal studies, especially following students into the field and employment, and multi professions would deepen our understanding of the different stages of PI development and highlight any similarities between the professions, enhancing curriculum development to best prepare students for future practice. 
SCOPING REVIEW: DEVELOPING PROFESSIONAL IDENTITY AND PROFESSIONAL SOCIALISATION

\section{Acknowledgments}

The authors would like to acknowledge the contribution of an Australian Government Research Training Program Scholarship in supporting this research.

\section{Funding and conflicts of interest}

None

\section{References}

Adams, K., Hean, S., Sturgis, P., \& Macleod Clark, J. (2006). Investigating the factors influencing professional identity of first-year health and social care students.

Learning in Health and Social Care, 5(2), 55-68. https://doi.org/10.1111/j.14736861.2006.00119.x

Ajjawi, R., \& Higgs, J. (2008). Learning to reason: A journey of professional socialisation. Advances in Health Sciences Education: Theory and practice, 13(2), 133-150. https://doi.org/10.1007/s10459-006-9032-4

Allied Health Professions Australia. (2017). What is allied health? https://ahpa.com. au/what-is-allied-health/

Anderson, D. K., \& Irwin, K. E. (2013). Self-assessment of professionalism in physical therapy education. Work, 44(3), 275-281. https://doi.org/10.3233/ WOR-121504

Arksey, H., \& O'Malley, L. (2005). Scoping studies: Towards a methodological framework. International Journal of Social Research Methodology, 8(1), 19-32. https://doi.org/10.1080/1364557032000119616

Ashby, S. E., Adler, J., \& Herbert, L. (2016). An exploratory international study into occupational therapy students' perceptions of professional identity. Australian Occupational Therapy Journal, 63(4), 233-243. https://doi.org/10.1111/14401630.12271

The Association of Schools of Allied Health Professions. (2015). What is allied health? http://www.asahp.org/what-is/

Australian Allied Health Leadership Forum. (2018). What is allied health? https:// aahlf.com/what-is-allied-health/

Barretti, M. A. (2007). Teachers and field instructors as student role models: A neglected dimension in social work education. Journal of Teaching in Social Work, 27(3), 215-239. https://doi.org/10.1300/J067v27n03_14

Bartlett, D. J., Lucy, S. D., Bisbee, L., \& Conti-Becker, A. (2009). Understanding the professional socialization of Canadian physical therapy students: A qualitative investigation. Physiotherapy Canada, 61(1), 15-25. https://doi.org/10.3138/ physio.61.1.15 
Bennett, D., Richardson, S., \& MacKinnon, P. (2016). Enacting strategies for graduate employability: How universities can best support students to develop generic skills: Final report 2016 (Part A). Australian Government, Office for Learning and Teaching, Department of Education and Training. https://melbourne-cshe.unimelb.edu. au/_data/assets/pdf_file/0011/1874774/SP13-3258_Curtin_Bennett_GraduateEmployability_Final-Report_Part-A_20163.pdf

Binyamin, G. (2018). Growing from dilemmas: Developing a professional identity through collaborative reflections on relational dilemmas. Advances in Health Sciences Education, 23, 43-60. https://doi.org/10.1007/s10459-017-9773-2

Black, L. L., Jensen, G. M., Mostrom, E., Perkins, J., Ritzline, P. D., Hayward, L., \& Blackmer, B. (2010). The first year of practice: An investigation of the professional learning and development of promising novice physical therapists. Physical Therapy, 90(12), 1758-1773. https://doi.org/10.2522/ptj.20100078

Boehm, J., Tanner, B., Lowrie, D., Bonassi, M., Brown, N., Thomas, Y., \& Cordier, R. (2015). Exploring emerging occupational therapy identity and the development of graduate attributes among occupational therapy students. British Journal of Occupational Therapy, 78(8), 499-507. https://doi. org/10.1177/0308022614562585

Bonsaksen, T., Grana, K. E., Celo, C., Ellingham, B., \& Myraunet, I. (2013). A practice placement design facilitating occupational therapy students' learning. The Journal of Mental Health Training, Education and Practice, 8(4), 169-10. https:// doi.org/10.1108/JMHTEP-08-2012-0028

Brown, D. L., Ferrill, M. J., Hinton, A. B., \& Shek, A. (2001). Self-directed professional development: The pursuit of affective learning. American Journal of Pharmaceutical Education, 65(3), 240-246. https://www.scopus.com/inward/ record.uri?eid=2-s2.0-0141451471\&partnerID=40\&md5=de7cab0de6a27ae26a2 $3136553 \mathrm{~d} 5 \mathrm{c} 888$

Burford, B., Morrow, G., Rothwell, C., Carter, M., \& Illing, J. (2014). Professionalism education should reflect reality: Findings from three health professions. Medical Education, 48(4), 361-374. https://doi.org/10.1111/ medu. 12368

Canavan, M. (2009). Professional identity formation and voluntary sector social work: Messages from an evaluation of a "flexible learning" programme in Northern Ireland. Journal of Practice Teaching and Learning, 9(3), 47-71. https:// doi.org/10.1921/ 146066910X541638

Clarke, C., Martin, M., Sadlo, G., \& de-Visser, R. (2014). The development of an authentic professional identity on role-emerging placements. British Journal of Occupational Therapy, 77(5), 222-229. https://doi.org/10.4276/03080221 4X13990455043368

Clarke, M. (2017). Rethinking graduate employability: The role of capital, individual attributes and context. Studies in Higher Education, 1-15. https://doi.org/10.1080/ 03075079.2017.1294152 
Clouder, L. (2003). Becoming professional: Exploring the complexities of professional socialization in health and social care. Learning in Health or Social Care, 2(4), 213-222. https://doi.org/10.1046/j.1473-6861.2003.00052.x

Collins, M., Harrison, D., Mason, R., \& Lowden, A. (2011). Innovation and creativity: Exploring human occupation and professional development in student education. British Journal of Occupational Therapy, 74(6), 304-308. https://doi.org /10.4276/030802211X13074383958020

Crandell, C. E., Wiegand, M. R., \& Brosky, J. A., Jr. (2013). Examining the role of service-learning on development of professionalism in doctor of physical therapy students: A case report. Journal of Allied Health, 42(1), e25-e32.

Cruess, R. L., Cruess, S. R., Boudreau, J. D., Snell, L., \& Steinert, Y. (2014). Reframing medical education to support professional identity formation. Academic Medicine, 89(11), 1446-1451. https://doi.org/10.1097/ ACM.0000000000000427

Dahlgren, M., Richardson, B., \& Sjostrom, B. (2004). Professions as communities of practice. In J. Higgs, B. Richardson, \& Dahlgren, M. (Eds.), Developing practice knowledge for health professionals (pp. 71-88). Butterworth Heinemann.

Daniels, J., \& Brooker, J. (2014). Student identity development in higher education: Implications for graduate attributes and work-readiness. Educational Research, 56(1), 1-12. https://doi.org/10.1080/00131881.2013.874157

Daudt, H. M. L., van Mossel, C., \& Scott, S. J. (2013). Enhancing the scoping study methodology: A large, inter-professional team experience with Arksey and O'Malley's framework. BMC Medical Research Methodology, 13(48). https://doi. org/10.1186/1471-2288-13-48

Davis, J. (2006). The importance of the community of practice in identity development. Internet Journal of Allied Health Sciences \& Practice, 4(3), 1-8. https://nsuworks.nova.edu/ijahsp/vol4/iss3/5/

Davis, J. (2008). Occupational therapy students' metaphors for helping. American Journal of Occupational Therapy, 62(2), 242-250. https://doi.org/10.5014/ ajot.62.2.242

Demo, D., Fry, D., Devine, N., \& Butler, A. (2015). A call for action: Advocating for increased funding for the allied health professions. Journal of Allied Health, 44(1), 57-62. https://www.ingentaconnect.com/content/asahp/ jah/2015/00000044/00000001/art00010\#expand/collapse

du Toit, D. (1995). A sociological analysis of the extent and influence of professional socialization on the development of a nursing identity among nursing students at two universities in Brisbane, Australia. Joumal of Advanced Nursing, 21(1), 164171. https://doi.org/10.1046/j.1365-2648.1995.21010164.x 
Frenk, J., Chen, L., Bhutta, Z., Cohen, J., Crisp, N., Evans, T., Fineberg, H., Garcia, P., Ke, Y., Kelley, P., Kistnasamy, B., Meleis, A., Naylor, D., Pablos-Mendez, A., Reddy, S., Scrimshaw, S., Sepulveda, J., Serwadda, D., \& Zurayk, H. (2010). Health professionals for a new century: Transforming education to strengthen health systems in an interdependent world. The Lancet, 376(9756), 1923-1958. https://doi.org/10.1016/S0140-6736(10)61854-5

Furze, J., Black, L., Peck, K., \& Jensen, G. M. (2011). Student perceptions of a community engagement experience: Exploration of reflections on social responsibility and professional formation. Physiotherapy Theory \& Practice, 27(6), 411-421. https://doi.org/10.3109/09593985.2010.516479

Gazzola, N., De Stefano, J., Audet, C., \& Theriault, A. (2011). Professional identity among counselling psychology doctoral students: A qualitative investigation. Counselling Psychology Quarterly, 24(4), 257-275. https://doi.org/10.1080/095150 70.2011 .630572

Gould, N. (1993). Cognitive change and learning from practice: A longitudinal study of social work students. Social Work Education, 12(1), 77-87. https://doi. org/10.1080/02615479311220071

Grace, S., \& Trede, F. (2013). Developing professionalism in physiotherapy and dietetics students in professional entry courses. Studies in Higher Education, 38(6), 793-806. https://doi.org/10.1080/03075079.2011.603410

Greenfield, B., Bridges, P., Phillips, T., Adams, E., Bullock, D., Davis, K., Nelson, C., \& Wood, B. (2015). Reflective narratives by physical therapist students on their early clinical experiences: A deductive and inductive approach. Journal of Physical Therapy Education, 29(2), 21-31. https://doi.org/10.1097/ JTE.0000000000000005

Grimmer, K., Lizarondo, L., Kumar, S., Bell, E., Buist, M., \& Weinstein, P. (2014). An evidence-based framework to measure quality of allied health care. Health Research Policy and Systems, 12, Article 10. https://doi.org/10.1186/1478-4505-1210

Hall, P. (2005). Interprofessional teamwork: Professional cultures as barriers. Journal of Interprofessional Care, 19(S1), 188-196. https://doi. org/10.1080/13561820500081745

Hantman, S., \& Ben-Oz, M. (2014). There are no shortcuts: Trusting the social work training process. Journal of Social Work, 14(5), 491-505. https://doi. org/10.1177/1468017313478351

Hayward, L. M., \& Li, L. (2014). Promoting and assessing cultural competence, professional identity, and advocacy in Doctor of Physical Therapy (DPT) degree students within a community of practice. Journal of Physical Therapy Education, 28(1), 23-36. https://insights.ovid.com/physical-therapy-education/ jopte/2014/10/000/promoting-assessing-cultural-competence/5/00001416 
Hean, S., \& Dickson, C. (2005). The contact hypothesis: An exploration of its further potential in interprofessional education. Journal of Interprofessional Care, 5(19), 480-491. https://doi.org/10.1080/13561820500215202

Holland, K., Middleton, L., \& Uys, L. (2012). The sources of professional confidence in occupational therapy students. Scandinavian Journal of Occupational Therapy, 42(3), 19-25. https://doi.org/10.1097/00001416-201301000-00013

Holmboe, S. E., \& Batalden, S. P. (2015). Achieving the desired transformation: Thoughts on next steps for outcomes-based medical education. Academic Medicine, 90(9), 1215-1223. https://doi.org/10.1097/ACM.0000000000000779

Howkins, E. J., \& Ewens, A. (1999). How students experience professional socialisation. International Journal of Nursing Studies, 35(1), 41-49. https://doi. org/10.1016/S0020-7489(98)00055-8

Ikiugu, M., \& Rosso, H. (2003). Facilitating professional identify in occupational therapy students. Occupational Therapy International, 10(3), 206-225. https://doi. org/10.1002/oti.186

Jackson, D. (2017). Developing pre-professional identity in undergraduates through work-integrated learning. Higher Education, 74(5), 833-853. https://doi. org/10.1007/s10734-016-0080-2

Jee, S. D., Schafheutle, E. I., \& Noyce, P. R. (2017). Using longitudinal mixed methods to study the development of professional behaviours during pharmacy work-based training. Health and Social Care in the Community, 25(3), 975-986. https://doi.org/10.1111/hsc.12397

Johnson, J. L., \& Chauvin, S. (2016). Professional identity formation in an advanced pharmacy practice experience emphasizing self-authorship. American Journal of Pharmaceutical Education, 80(10), Article 172. https://doi.org/10.1111/hsc.12397

Jollands, M., Clarke, B., Grando, D., Hamilton, M., Smith, J., Xenos, S., Brodie, M., \& Burton, A. (2015). Developing graduate employability through partnerships with industry and professional associations. Australian Government, Office for Learning and Teaching, Department of Education and Training. https://tr.edu.au/resources/ SP13_3256_Jollands_Report_2015.pdf

Joynes, V. C. T. (2018). Defining and understanding the relationship between professional identity and interprofessional responsibility: Implications for educating health and social care students. Advances in Health Sciences Education, 23(1), 133-149. https://doi.org/10.1007/s10459-017-9778-x

Khalili, H., Orchard, C., Spence Laschinger, H. K., \& Farah, R. (2013). An interprofessional socialization framework for developing an interprofessional identity among health professions students. Journal of Interprofessional Care, 27(6), 448-453. https://doi.org/10.3109/13561820.2013.804042

Knightbridge, L. (2014). Experiential learning on an alternative practice education placement: Student reflections on entry-level competency, personal growth, and future practice. British Journal of Occupational Therapy, 77(9), 438-446. https:// doi.org/10.4276/030802214X14098207540956 
Lahav, O., Daniely, N., \& Yalon-Chamovitz, S. (2017). Interpersonal social responsibility model of service learning: A longitudinal study. Scandinavian Journal of Occupational Therapy, 25(1), 61-69. https://doi.org/10.1080/11038128.2017.1 335775

Lerkiatbundit, S. (2006). Factor structure and cross-validation of a professionalism scale in pharmacy students. Journal of Pharmacy Teaching, 12(2), 25-49. https:// doi.org/10.1300/J060v12n02_03

Levac, D., Colquhoun, H., \& Brien, K. K. (2010). Scoping studies: Advancing the methodology. Implementation Science, 5, Article 69. https://doi.org/10.1186/17485908-5-69

Levy, D., Shlomo, S. B., \& Itzhaky, H. (2014). The "building blocks" of professional identity among social work graduates. Social Work Education, 33(6), 744-759. https://doi.org/10.1080/02615479.2014.883600

Li, L. C., Grimshaw, J. M., Nielsen, C., Judd, M., Coyte, P. C., \& Graham, I. D. (2009). Use of communities of practice in business and health care sectors: A systematic review. Implementation Science, 4, Article 27. https://doi. org/10.1186/1748-5908-4-27

Liamputtong, P. (2013). Making sense of qualitative data: The analysis process. In P. Liamputtong (Ed.), Qualitative Research Methods (4th ed.) (pp. 241-263). Oxford University Press.

Liberati, A., Altman, D. G., Tetzlaff, J., Mulrow, C., Gøtzsche, P. C., Ioannidis, J. P. A., Clarke, M., Devereaux, P. J., Kleijnen, J., \& Moher, D. (2009). The PRISMA statement for reporting systematic reviews and meta-analyses of studies that evaluate health care interventions: Explanation and elaboration. Annals of Internal Medicine, 151(4), W65-W94. https://doi.org/10.7326/0003-4819-1514-200908180-00136

Lindquist, I., Engardt, M., Garnham, L., Poland, F., \& Richardson, B. (2006a). Development pathways in learning to be a physiotherapist. Physiotherapy Research International, 11(3), 129-139. https://doi.org/10.1002/pri.332

Lindquist, I., Engardt, M., Garnham, L., Poland, F., \& Richardson, B. (2006b). Physiotherapy students' professional identity on the edge of working life. Medical Teacher, 28(3), 270-276. https://doi.org/10.1080/01421590600605272

Lindsey, E. W. (2005). Study abroad and values development in social work students. Journal of Social Work Education, 41(2), 229-249. https://doi.org/10.5175/ JSWE.2005.200303110

Loseke, D. R., \& Cahill, S. E. (1986). Actors in search of a character: Student social workers' quest for professional identity. Symbolic Interaction, 9(2), 245-258. https://doi.org/10.1525/si.1986.9.2.245

MacLellan, D., Lordly, D., \& Gingras, J. (2011). Professional socialization in dietetics: A review of the literature. Canadian Journal of Dietetic Practice and Research, 72(1), 37-42. https://doi.org/10.3148/72.1.2011.37 
SCOPING REVIEW: DEVELOPING PROFESSIONAL IDENTITY AND PROFESSIONAL SOCIALISATION

Mason, J. (2013). Review of Australian Government Health Workforce Programs. https:// www1.health.gov.au/internet/main/publishing.nsf/Content/review-australiangovernment-health-workforce-programs

McAllister, L., \& Nagarajan, S. (2015). Accreditation requirements in allied health education: Strengths, weaknesses and missed opportunities. Journal of Teaching and Learning for Graduate Employability, 6(1), 2-24. https://doi.org/10.21153/ jtlge2015vol6nolart570

Miller, S. E. (2010). A conceptual framework for the professional socialization of social workers. Journal of Human Behavior in the Social Environment, 20(7), 924-938. https://doi.org/10.1080/10911351003751934

Miller, S. E. (2013). Professional socialization: A bridge between the explicit and implicit curricula. Journal of Social Work Education, 49(3), 368-386. https://doi. org/10.1080/10437797.2013.796773

Mylrea, M. F., Gupta, T. S., \& Glass, B. D. (2015). Professionalization in pharmacy education as a matter of identity. American Journal of Pharmaceutical Education, 79(9), Article 142. https://www.scopus.com/inward/record.uri? eid=2-s2.084954428149\&partnerID $=40 \& \mathrm{md} 5=5 \mathrm{f} 4 \mathrm{e} 063 \mathrm{eb} 116939 \mathrm{fc} 31705 \mathrm{c} 01 \mathrm{fc} 55 \mathrm{a} 88$

National Library of Medicine. (2018). Medicine subject headings (MeSH). https:// meshb.nlm.nih.gov/search

Noble, C., Coombes, I., Nissen, L., Shaw, P. N., \& Clavarino, A. (2015). Making the transition from pharmacy student to pharmacist: Australian interns' perceptions of professional identity formation. International Journal of Pharmacy Practice, 23(4), 292-304. https://doi.org/10.1111/ijpp.12155

Noble, C., Coombes, I., Shaw, P. N., Nissen, L. M., \& Clavarino, A. (2014). Becoming a pharmacist: The role of curriculum in professional identity formation. Pharmacy Practice, 12(1), 380. https://pharmacypractice.org/journal/index.php/ $\mathrm{pp} /$ article/view/380

Noble, C., O’Brien, M., Coombes, I., Shaw, P. N., Nissen, L., \& Clavarino, A. (2014). Becoming a pharmacist: Students' perceptions of their curricular experience and professional identity formation. Currents in Pharmacy Teaching and Learning, 6(3), 327-339. https://doi.org/10.1016/j.cptl.2014.02.010

O'Brien, K. K., Colquhoun, H., Levac, D., Baxter, L., Tricco, A. C., Straus, S., Wickerson, L., Nayar, A., Moher, D., \& O'Malley, L. (2016). Advancing scoping study methodology: A web-based survey and consultation of perceptions on terminology, definition and methodological steps. BMC Health Services Research, 16, Article 305. https://doi.org/10.1186/s12913-016-1579-z

O'Loughlin, K., Dal Bello-Haas, V., \& Milidonis, M. (2005). The professional development plan: Cultivation of professional development and lifelong learning in professional (entry-level) physical therapist students. Journal of Physical Therapy Education, 19(2), 42-51. https://doi.org/10.1097/00001416-200507000-00006 
Oandasan, I., \& Reeves, S. (2005). Key elements for interprofessional education. Part 1: The learner, the educator and the learning context. Journal of Interprofessional Care, 19, (Suppl. 1), 21-38. https://doi.org/10.1080/13561820500083550

Osteen, P. J. (2011). Motivations, values, and conflict resolution: Students integration of personal and professional identities. Journal of Social Work Education, 47(3), 423-444. https://doi.org/10.5175/JSWE.2011.200900131

Ouzzani, M., Hammady, H., Fedorowicz, Z., \& Elmagarmid, A. (2016). Rayyan: A web and mobile app for systematic reviews. Systematic Reviews, 5, Article 210. https://doi.org/10.1186/s13643-016-0384-4

Paterson, J., Higgs, J., Wilcox, S., \& Villeneuve, M. (2002). Clinical reasoning and self-directed learning: Key dimensions in professional education and professional socialisation. Focus on Health Professional Education: A Multi-disciplinary Journal, 4(2), 5-21.

Pullen Sansfaçon, A., \& Crête, J. (2016). Identity development among social workers, from training to practice: Results from a three-year qualitative longitudinal study. Social Work Education, 35(7), 767-779. https://doi.org/0.1080/02615479.2016.1 211097

Ranmuthugala, G., Plumb, J., Cunningham, F., Georgiou, A., Westbrook, J., \& Braithwaite, J. (2011). How and why are communities of practice established in the healthcare sector? A systematic review of the literature. BMC Health Service Research, 11, Article 273. https://doi.org/10.1186/1472-6963-11-273

Richardson, B., Lindquist, I., Engardt, M., \& Aitman, C. (2002). Professional socialization: Students' expectations of being a physiotherapist. Medical Teacher, 24(6), 622-627. https://doi.org/10.1080/0142159021000063943

Robinson, A. J., Tanchuk, C. J., \& Sullivan, T. M. (2012). Professionalism and occupational therapy: An exploration of faculty and students' perspectives. Canadian Journal of Occupational Therapy, 79(5), 275-284. https://doi. org/10.2182/cjot.2012.79.5.3

Rutter, P. M., \& Duncan, G. (2010). Can professionalism be measured? Evidence from the pharmacy literature. Pharmacy Practice, 8(1), 18-28. https://doi. org/10.4321/S1886-36552010000100002

Roche, A., \& Coote, S. (2008). Focus group study of student physiotherapists' perceptions of reflection. Medical Education, 42(11), 1064-1070. https://doi. org/10.1111/j.1365-2923.2008.03178.x

Santasier, A. M., \& Plack, M. M. (2007). Assessing professional behaviors using qualitative data analysis. Journal of Physical Therapy Education, 21(3), 29-39. https://doi.org/10.1097/00001416-200710000-00005

Scholar, H., McLaughlin, H., McCaughan, S., \& Coleman, A. (2014). Learning to be a social worker in a non-traditional placement: Critical reflections on social work, professional identity and social work education in England. Social Work Education, 33(8), 998-1016. https://doi.org/10.1080/02615479.2014.926320 
Shlomo, S. B., Levy, D., \& Itzhaky, H. (2012). Development of professional identity among social work students: Contributing factors. Clinical Supervisor, 31(2), 240-255. https://doi.org/10.1080/07325223.2013.733305

Shuval, J. T., \& Adler, I. (1979). Health occupations in Israel: Comparative patterns of change during socialization. Journal of Health and Social Behavior, 20(1), 77-89. http://www.jstor.org/stable/2136482

Skøien, A. K., Vågstøl, U., \& Raaheim, A. (2009). Learning physiotherapy in clinical practice: Student interaction in a professional context. Physiotherapy Theory \& Practice, 25(4), 268-278. https://doi.org/10.1080/09593980902782298

Smith, R. A., \& Pilling, S. (2007). Allied health graduate program: Supporting the transition from student to professional in an interdisciplinary program. Journal of Interprofessional Care, 21(3), 265-276. https://doi. org/10.1080/13561820701259116

Swanepoel, E., Tweedie, J., \& Maher, J. (2016). Building dietetic student confidence and professional identity through participation in a university health clinic. Nutrition \& Dietetics, 73(3), 229-234. https://doi.org/10.1111/1747-0080.12268

Taylor, K. M. G., \& Harding, G. (2007). The pharmacy degree: The student experience of professional training. Pharmacy Education, 7(1), 83-88. https://doi. org/10.1080/15602210601149383

Trede, F., Macklin, R., \& Bridges, D. (2012). Professional identity development: A review of the higher education literature. Studies in Higher Education, 37(3), 365-384. https://doi.org/10.1080/03075079.2010.521237

Tricco, A. C., Cardoso, R., Thomas, S. M., Motiwala, S., Sullivan, S., Kealey, M. R., Hemmelgarn, B., Ouimet, M., Hillmer, M. P., Perrier, L., Shepperd, S., \& Straus, S. E. (2016). Barriers and facilitators to uptake of systematic reviews by policy makers and health care managers: A scoping review. Implementation Science, 11, Article 4. https://doi.org/10.1186/s13012-016-0370-1

Tryssenaar, J., \& Perkins, J. (2001). From student to therapist: Exploring the first year of practice. American Journal of Occupational Therapy, 55(1), 19-27. https://doi. org10.5014/ajot.55.1.19

Tsoumas, L. J., \& Pelletier, D. (2007). Integrating professional behavior development across a professional allied health curriculum. Journal of Allied Health, 36(4), e313-e325. https:/www.ingentaconnect.com/content/asahp/ jah/2007/00000036/00000004/art00013

Turnbull, C., Grimmer-Somers, K., Kumar, S., May, E., Law, D., \& Ashworth, E. (2009). Allied, scientific and complementary health professionals: A new model for Australian allied health. Australian Health Review, 33(1), 27-37. https://doi. org/10.1097/00001416-201301000-00013

Turpin, M. J., Rodger, S., \& Hall, A. R. (2012). Occupational therapy students' perceptions of occupational therapy. Australian Occupational Therapy Journal, 59(5), 367-374. https://doi.org/10.1111/j.1440-1630.2011.00988.x 
Whitcombe, S. W. (2013). Problem-based learning students' perceptions of knowledge and professional identity: Occupational therapists as "knowers". British Journal of Occupational Therapy, 76(1), 37-42. https://doi.org/10.4276/03080221 3X13576469254739

Wiles, F. (2013). "Not easily put into a box": Constructing professional identity. Social Work Education, 32(7), 854-866. https://doi.org/10.1080/02615479.2012. 705273

Wilkes, M., Cassel, C., \& Klau, M. (2018). If we keep doing what we're doing we'll keep getting what we're getting: A need to rethink "academic" medicine. Medical Teacher, 4O(4), 364-371. https://doi.org/10.1080/0142159X.2017.1417580

Wise, H. H., \& Yuen, K. (2013). Effect of community-based service learning on professionalism in student physical therapists. Journal of Physical Therapy Education, 27(2), 58-64. https://doi.org/10.1097/00001416-201301000-00013

World Health Organisation (WHO). (1988). Learning together to work together for health: Report of a WHO study group on multiprofessional education for health personnel: The team approach (Technical Report Series 769:1-72). http://who.int/ iris/handle/10665/37411.

World Health Organisation (WHO). (2010). Framework for action on interprofessional education and collaborative practice (Reference No: WHO/HRH/HPN/10.3). http://www.who.int/hrh/resources/framework_action/en/ 


\title{
SCOPING REVIEW: DEVELOPING PROFESSIONAL IDENTITY AND PROFESSIONAL SOCIALISATION
}

\section{Appendix}

\author{
Search in Ovid Medline
}

Ovid MEDLINE(R) and Epub Ahead of Print, In-Process \& Other Non-Indexed Citations, Daily and Versions(R) 1946 onwards

1. allied health occupations/ or audiology/ or occupational therapy/ or physical therapy specialty/ or speech-language pathology/ or pharmacy/

2. allied health personnel/ or nutritionists/ or physical therapists/

3. Pharmacists/

4. Nutritionists/

5. Occupational Therapy/

6. Physical Therapists/

7. Social Workers/

8. Podiatry/

9. Psychology/

10. language therapy/ or speech therapy/ or voice training/

11. ("allied health occupation*" or "allied health profession*" or "allied health practitioner*" or "allied health personnel" or "health and social care professional*" or audiolog* or physiotherap* or "physical therap*" or "occupational therap*" or "speech therap*" or "speech patholog*" or dietician or dietetic* or nutritionist* or "social work*" or psycholog* or podiatr* or pharmac*).ti,ab.

\section{2. $\mathrm{OR} / 1-11$}

13. students/ or students, health occupations/ or students, pharmacy/ or students, public health/

14. education, professional/ or education, pharmacy, graduate/ or exp education, pharmacy/ or education, public health professional/

15. (student* or "university student*" or "tertiary student*" or "higher education student*" or baccalaureate).ti,ab.

16. ("university education" or "tertiary education" or "higher education program*"). ti,ab.

17. ("health professional educat*" or "health professional student*" or "health occupational training program*" or "health sciences educat*" or "clinical educat*" or "allied health student*"). ti,ab.

18. pre-registration or preregistration or prelicens* or pre-licens*

19. $0 \mathrm{R} / 13-18$

20. Professional Role/ OR Social Identification/

21. ("professional identity" or "professional sociali?ation" or "professional role*" or professionali?ation or "professional identity development" or "professional identity formation" or "occupational identity" or "identity development").ti,ab.

22. $0 \mathrm{R} / 20-21$

23. 12 AND 19 AND 22 